\title{
Adjusting Inter-censal Population Estimates for Germany 1987-2011: Approaches and Impact on Demographic Indicators*
}

\author{
Sebastian Klüsener, Pavel Grigoriev, Rembrandt D. Scholz, \\ Dmitri A. Jdanov
}

\begin{abstract}
To derive reliable demographic indicators, appropriate data on population exposures are needed. Access to such data is becoming increasingly challenging in many countries due to factors such as the growing diversity of international migration patterns and the trend towards replacing full censuses with register-based censuses. Germany represents a particularly challenging case in this respect. Before Germany implemented its first register-based census in 2011, the country had not conducted a census for more than two decades. This census revealed that the number of people living in Germany in 2011 was about 1.5 million lower than the previous official post-censal population estimates for that year indicated. It is likely that a large portion of this discrepancy had existed for quite some time prior to 2011. Due to the long inter-censal period, the Federal Statistical Office of Germany decided not to produce backward-adjusted population estimates by single-year ages and sex for the whole period. The main aim of this paper is thus to make such detailed adjusted inter-censal population estimates available. While we have to take the peculiarities of the German case into account, our evaluation of different strategies offers important insights for developing a generalised methodology to adjust inter-censal population estimates for globalised countries that face challenges in ensuring the proper registration of migration events. We discuss four alternative approaches for deriving adjusted inter-censal population estimates. The results suggest that even for a rather complicated case like Germany, a relatively simple approach seems to work reasonably well. Finally, we demonstrate to what extent the implemented adjustments affect mortality indicators. The adjusted inter-censal population estimates for Germany and its federal states are provided in the online data appendix.
\end{abstract}

Keywords: Inter-censal population estimates · Germany · Adjustment methods

\footnotetext{
This article contains supplementary material in the form of an Online and a Data Appendix DOI 10.12765/CPoS-2018-06en, DOI 10.12765/CPoS-2018-07en

URL: http://www.comparativepopulationstudies.de/index.php/CPoS/article/view/251/264

URL:http://www.comparativepopulationstudies.de/index.php/CPoS/article/view/251/265.
} 


\section{Motivation, challenges, and definitions}

To obtain reliable and comparable information on demographic phenomena such as mortality, fertility, and migration, it is vital to have access to high-quality data on the population at risk. This issue is particularly relevant for international comparative database projects, such as the Human Mortality Database (HMD) (HMD 2017; Barbieri et al. 2015) and the Human Fertility Database (HFD) (HFD 2017; Jasilioniene et al. 2016). A number of developments have made obtaining reliable information on population exposures increasingly challenging, even for high-income countries. The inappropriate measurement of international migration is an important source of error in deriving population estimates. The chances that international migration events are measured incorrectly have increased in recent years as international migration has become less dominated by permanent country A to country B relocations than by other forms of migration with more complex migration trajectories. These new patterns are also referred to as super-diversity (Meissner/Vertovec 2015). Within the European Union, such tendencies have been fostered by the elimination of almost all restrictions on the movement of people between European Union member states (Castro-Martín/Cortina 2015). Another reason why obtaining accurate demographic data has become difficult is that a growing number of countries, including Germany, have transitioned from conducting traditional full censuses to performing registerbased censuses (Valente 2010). The question of whether a register-based census is able to deliver results that are similar in quality to those of a traditional census is a matter of dispute (Coleman 2013; Martin 2006). In light of the increasing challenges population scientists face in obtaining reliable population data for countries subject to substantial (international) migration, it is essential that researchers carefully reassess and seek to enhance existing methodologies to produce backward-adjusted inter-censal population estimates.

We believe that Germany is particularly well-suited for such an evaluation. The official German population statistics for the last four decades provide us with a multitude of challenges. These challenges largely stem from the fact that, for various reasons, there were long gaps between the censuses of 1981 in East Germany ${ }^{1}$ and of 1987 in West Germany, and the most recent census of 2011. ${ }^{2}$ The 2011 census was not only the first census conducted in Germany following reunification in 1990; it was also the first register-based census carried out in Germany (see also Klüsener) Zagheni 2014).

The situation in Germany is further complicated by the high internal and international migration rates the country experienced in the late 1980s and the early 1990s surrounding the fall of the Iron Curtain and German reunification. Since large shares of the errors in the official population estimates are attributable to the misreport-

1 In this paper, the terms East and West Germany refer to the territories of the former German Democratic Republic (including East Berlin) and of the Federal Republic of Germany (including West Berlin) for the periods both before and after the reunification of Germany in 1990.

For a discussion of the factors that led to the long inter-censal period, see, e.g., Eppmann (2004). 
ing of migration events, it is very likely that substantial distortions occurred at the beginning of this long inter-censal period, and that a non-negligible share of these early errors continued to distort population estimates over the almost two decades that passed before the census of 2011 was finally conducted (see also Kaus/MundilSchwarz 2015).

These challenges might explain the decision made by the Federal Statistical Office of Germany not to produce corrected population estimates by age and sex for the entire inter-censal period. As these data are needed to derive appropriate population exposures for the HMD and the HFD, we decided to use the German case to evaluate and enhance the methodologies for adjusting inter-censal population estimates. While it is clear that we also need to account for the specificities of the German case, our evaluation of different inter-censal population adjustment strategies offers valuable insights that can be used in developing a generalised methodology for obtaining adjusted inter-censal population estimates for globalised countries that are subject to substantial internal and international migration.

The applicability of the derived adjusted population estimates is certainly not limited to the aforementioned databases; the adjusted estimates can also be used for other purposes for which reliable estimates of the population at risk are needed. The obtained adjusted population estimates that were required for the HMD are available for download as so-called "input data" from this database (HMD 2017), while complete datasets derived through our preferred adjustment approach are available in a separate online data appendix of this paper. These datasets include data for East, West, and total Germany, as well as data for the 16 German federal states and East and West Berlin. In this paper, however, we will focus on the adjustments for East, West, and total Germany, as data limitations prevented us from implementing all of the considered adjustment methods at the state level as well.

A general obstacle researchers encounter in attempting to adjust inter-censal population estimates is the decentralised system of statistics in Germany (Hö/der) Ehling 1991; von der Lippe 2006). Germany has a federalised structure in which the responsibility for collecting statistics is assigned to the 16 federal states and their statistical offices. ${ }^{3}$ The Federal Statistical Office of Germany mainly plays a moderating role, and has only limited access to the raw data collected by the state statistical offices. While the population data collection procedures and the definitions used are largely harmonised across the federal states, there are vast differences in how each state deals with population data distortions. The statistical offices of the German states and the local registry offices that are in charge of the population registers were certainly aware that during the long inter-censal period - and especially during the turbulent period around the time of German reunification - substantial biases had been introduced into the population estimates due to misreported migration events. Thus, efforts were made as part of state-level and local initiatives to

3 Recently, the German states of Schleswig-Holstein and Hamburg as well as the states of Brandenburg and Berlin have merged their statistical offices, which reduced the total number to 14 . 
identify erroneous cases and to take them out of the population statistics. If, for example, evidence was found that a single individual had been counted in the statistics more than once, the incorrect entries were removed. The standard procedure for such removals is to assign an artificial out-migration move abroad to the double entry. Unfortunately, in most instances it is not possible to distinguish between real and artificial out-migration events. Over the course of the last inter-censal period, such correction procedures were implemented at different points in time and with varying degrees of intensity across the German states. This variation in cleaning intensities seems to partially explain why after the last census some of the German states needed to introduce fewer corrections to their population numbers than others.

It is important to stress that many of these corrections were introduced in the mid- to late 2000s, shortly before the 2011 census. But it is reasonable to assume that a considerable percentage of the erroneous entries that were corrected in this period had originated in the period of German reunification (see also below), and had thus caused distortions in the population estimates for long periods of time. The implemented corrections complicated our work, as they made it more difficult for us to identify the full volume of errors that had accumulated over the inter-censal period. In this paper, we will use the term accumulated error to refer to the difference between 1.) the old post-censal population estimates (based on the $1981^{4}$ and 1987 censuses in East and West Germany, respectively); and 2.) the new official post-censal population estimates based on the 2011 census, as obtained on 1 January 2012. If we had looked only at the accumulated error based on the 2011 census results, we would have been unable to account for the temporary distortions that were eliminated in the corrections immediately before the census. Therefore, we had to develop procedures that allowed us to quantify the magnitude of these corrections. However, such an assessment could only be approximate. The estimated corrected cases were then added to the official post-censal population estimates based on the 1981 and 1987 censuses to derive a so-called prior-cleaning-adjusted accumulated error.

In addition to the challenges mentioned above, we had to overcome another obstacle. To ensure data comparability over time, the HMD maintains not just time series on Germany (from 1990 onwards), but also time series for the territories of East and West Germany into which Germany was divided between 1949 and 1990. As a result, East and West Berlin are still included in the territories of East and West

4 From the date of German reunification (3 October 1990) until the 2011 census, the official population estimates for East Germany had been based on an extract of the population register of the German Democratic Republic taken at the date of reunification. However, the Federal Statistical Office of Germany acknowledged that these register-extracted population estimates were probably too high due to the under-registration of out-migration abroad events from the German Democratic Republic in the late 1980s (Statistisches Bundesamt 2006: 30). Thus, in our inter-censal adjustment we will use the census of 1981 as the main reference point, and not the register-based extract from 1990. 
Germany, respectively (Scholz et al. 2017). ${ }^{5}$ But since 2001, when Berlin enacted an administrative reform, it has not been possible to derive data for the former territories of East and West Berlin directly from the city's published statistical data. To deal with this challenge, a method was developed as part of the HMD activities that allows researchers to obtain very precise estimates of demographic events, such as births and deaths, for the former territories of East and West Berlin from 2001 onwards (see Scholz et al. 2017). Since the HMD still recognises the historic division of East and West Berlin, our adjustment method should also be able to account for this distinction. 6,7

Another challenge we faced was that East and West Germany had conducted the censuses that preceded the 2011 census at different points in time (1981 and 1987, respectively). This gap was of relevance for our decision about how to define the beginning and the end of the inter-censal adjustment period. Given that the German Democratic Republic (GDR) maintained a highly reliable central population register, and that the levels of international migration to and from the GDR were rather low up to 1988 (Statistisches Bundesamt 1993), we can assume that the post-censal population estimates for the GDR are highly accurate up to the beginning of 1988 . Therefore, for East Germany we decided to set a so-called pseudo-census point of 1 January 1988. In West Germany, the official census date was 25 May 1987. To ensure comparability with the East German estimates, we decided to use for West Germany the population estimates for 1 January 1988, rather than the population numbers at the very beginning of the inter-censal period.

The final results of the 2011 census were published by the Federal Statistical Office in May 2013. However, the official German population estimates of the current post-censal period are based not on these data, but on modified data published in April 2015 (see Kaus/Mundil-Schwarz 2015). ${ }^{8}$ These modified data were also em-

5 The motivation for doing so is to support research that examines the effects of German reunification on the convergence of the large mortality differences that existed between East and West Germany in the 1980s.

6

Another territorial change that affected the borders of former East and West Germany occurred on 30 June 1993, when a small territory of former East Germany (Amt Neuhaus) was transferred to West Germany. However, due to the small population size of this territory (app. 4,800 inhabitants), this change is not specifically accounted for in the HMD and in our inter-censal adjustment.

7

The HFD applies from 1990 onwards a slightly different territorial definition of East and West Germany, which is congruent with the definition used by the Federal Statistical Office since 2001. According to this definition, East and West Berlin are, respectively, excluded from East and West Germany. Download links to data for these subdivisions are also available in the online data appendix.

8 The Federal Statistical Office of Germany decided not to use the published final results of the 2011 census as the basis for its future population estimates, as some of these data turned out to be implausible when compared with data from other sources, such as local population and birth registers. These inconsistencies are likely related to the fact that the 2011 census was not a full census, but was instead based on a register-drawn sample. To deal with the inconsistencies identified in the published census results, the Federal Statistical Office decided to use modified census results as the basis for its future population estimates. For the census date, these results provide the same total population number for Germany, while the population numbers broken down by age and sex have been adjusted based on additional information. To our knowledge, there is no published detailed documentation on how these adjustments were implemented. 
ployed for our adjustment. As the end point for our adjustment, we again did not use the estimates for the census date (9 May 2011), but rather the population estimates for 1 January 2012. The choice of this approach was guided by our intention to produce adjusted population estimates for the former territories of East and West Berlin. To derive such estimates, we had to rely on register data for Berlin, which we could only obtain for complete years. Thus, our adjusted inter-censal population estimates cover the period between 1 January 1988 and 1 January 2012.

The remainder of this paper is organised as follows. First, we provide background information on how errors in the population estimates can emerge (section 2). We then present an overview of the available raw data (section 3). Next, we describe the first major step of the adjustment procedure we used to identify official corrections to the population estimates implemented in the years prior to the 2011 census (section 4). We then provide an account of the second major step of our adjustment, in which we adjusted the population estimates within the inter-censal period based on assumptions about how the accumulated error identified at the end of the period accrued over time. In total, we considered and tested four adjustment procedures (section 5). This is followed by an assessment of the extent to which the mortality indicators based on our adjusted population estimates differ from those derived by the HMD or national and international institutions on the basis of the originally published population estimates (section 6). A discussion and conclusion is provided in section 7.

\section{Potential origins of the errors in the official population estimates}

Errors in the population statistics can occur for a number of reasons. Among the potential sources of error are problems with how the censuses are conducted. As we mentioned above, the 2011 census was the first register-based census in Germany, whereas all of the preceding censuses had been carried out as traditional censuses covering the entire population. Details on the methodology of the 2011 census have been provided by Kaus and Mundil-Schwarz (2015). An overview of the potential deficiencies of the 2011 census has been presented by Scholz and Kreyenfeld (2016). The challenges associated with implementing register-based censuses (see also Coleman 2013) are also reflected in the Federal Statistical Office's decision to base its current future population estimates not strictly on the population numbers derived in the 2011 census, but on modified numbers that take additional information into account. Nevertheless, compared to the old inter-censal estimates based on the 1981 and 1987 censuses, the 2011 census provided a much more accurate picture of the population living in Germany. While the quality of the last full West German census of 1987 has also been criticised (Grohmann 2009), we are not aware of any systematic shortcomings of the censuses of 1981, 1987, or 2011 that could be appropriately corrected. Thus, we decided not to make any modifications to the census data (or to the officially adjusted census data in case of the 2011 census). For 
the same reasons, we also chose not to modify the respective official population estimates for the beginning of years that succeeded a census or that were selected as pseudo-census points.

In Germany, the register data on births and deaths are highly reliable (Kreyen$\mathrm{fe} / \mathrm{d} / \mathrm{Scholz}$ 2009). But like in many other countries around the world, the German statistical offices are finding it difficult to ensure that migration events are measured in a comprehensive manner. The registration laws of Germany and the GDR have consistently stipulated that each individual resident is permitted to have only one primary residence. But when migration events are not registered or are registered incompletely, an individual may be registered as having more than one primary residence. Moreover, an individual who is no longer living in Germany may still be registered as a resident. These erroneous or multiple entries can cause an artificial inflation of the population statistics. One major source of error is the under-registration of out-migration abroad. Many foreign (predominantly male) migrants who came to (West) Germany as labour migrants in the second half of the $20^{\text {th }}$ century do not register their out-migration when they return to their home country. As a result, such migrants remain in the population estimates, even though they are no longer resident in Germany (see also Hannemann/Scholz 2009). The failure to register a return migration event can become particularly problematic if the individual dies while abroad and the death is not reported to the German authorities; as in such cases the deceased is likely to remain in the statistics as a living resident. The share of these 'dead souls' in the reported population estimates increases with age. This phenomenon is mostly concentrated in West Germany. East Germany, by contrast, attracted relatively few foreign migrant workers after 1950. Hence, the East German population estimates have been much less affected by the under-registration of outmigration after retirement than the West German estimates.

These East-West differences are also visible in Figure 1, which compares by age and sex the accumulated error as of 1 January 2012 in percent, while using as a reference the population estimates based on the officially corrected 2011 census outcomes for that date (blue bars; the stacked dark blue bars will be explained below). The impact of the under-registration of out-migration abroad on life expectancy trends at high ages has been well documented (Jdanov et al. 2005; Scholz) Jdanov 2007; Scholz/Jdanov 2008). This problem is still relevant today, and is likely to be an important source of distortion in the future. To account for this problem, the HMD applied for Germany during the inter-censal period a correction method that relied upon more accurate information from pension data (Scholz/Jdanov 2007). The comparison of the corrected population estimates at high ages and the population numbers obtained in the 2011 census showed that this methodology was very reliable (Scholz et al. 2017).

But not all of the shortcomings of the published official post-censal population estimates are related to cohorts of advanced ages. In Figure 1, we also observe deviations of up to around five percent among the cohorts born in the 1960s and the 1970s who were aged 31-51 in 2011. For these cohorts, notable deviations can be detected in both East and West Germany. Again, these patterns are more pronounced among males. The similarities between East and West Germany suggest 
Fig. 1: Deviation of population estimates based on the 1981 and 1987 censuses from population estimates based on the 2011 census in \% (1 January 2012) (without and with adjustment for prior cleaning)
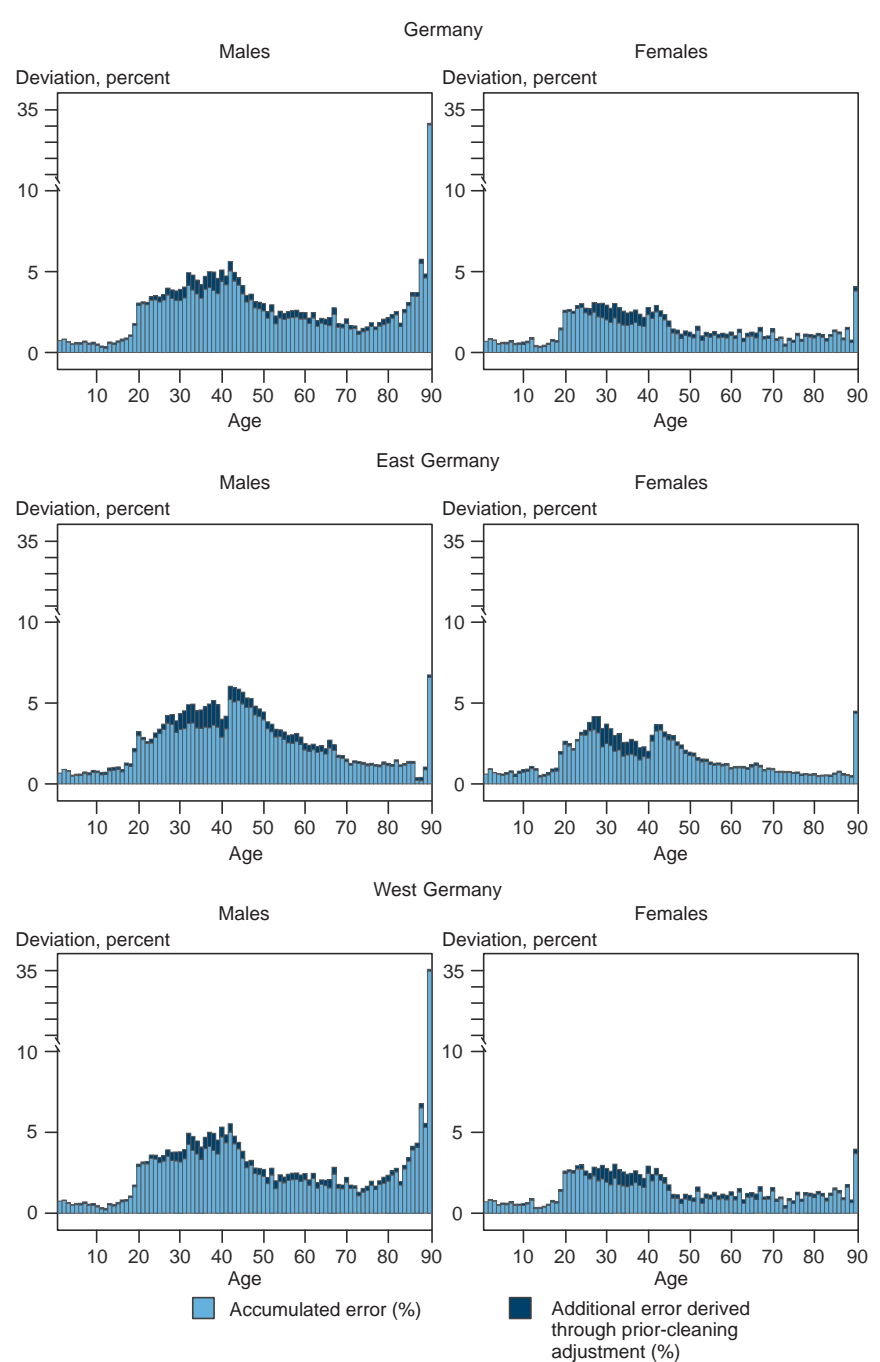

Note: The population estimates derived from the 2011 census are based on the officially corrected census data published by the Federal Statistical Office of Germany in April 2015. These numbers are used as a reference to derive the deviation of the old population estimates based on the 1981 and 1987 censuses. The accumulated error refers to the unadjusted deviation between the old and the new population estimates, while the additional error identifies the further deviation that we obtained when we adjusted for the prior cleaning of the statistics before the 2011 census. In this adjustment, which is described in detail in section 4, we aimed to revoke the prior cleaning by deriving an estimate of the cleaned cases, and adding them back to the population estimates based on the 1981 and 1987 censuses to get closer to the total deviation that emerged during the inter-censal period.

Source: Federal Statistical Office, own calculations 
that the errors among these cohorts originated from a process that affected both parts of Germany. To understand this issue, it is important to recognise that people's mobility levels are highest between ages 18 and 30 (Bell/Muhidin 2009). For the cohorts born in the 1960s and the 1970s, this age span coincides with the period around 1990, when migration intensified following the fall of the Iron Curtain and German reunification. It is therefore very likely that a substantial share of the accumulated errors in these cohorts originated during this rather chaotic period (see also Kaus/Mundil-Schwarz 2015).

Between 1988 and reunification, rates of out-migration from East Germany increased rapidly. Such moves were often irregular in nature, and the GDR authorities were not able to keep track of all migration events. Thus, some East German refugees and migrants to West Germany remained registered at their former address in East Germany. However, problems continued to occur after reunification due to the under-registration of both external and internal migration events, which likely led to erroneous or double entries in the population statistics. To fully understand the East-West migration patterns of the cohorts born in the 1960s and the 1970s, it is important to take into account that there was not only a massive outflow of people from East to West Germany starting in the late 1980s, but also a continuous wave of migrants returning to East Germany starting in the 1990s (Fuchs-Schünde/n/Schündeln 2009). In the early 1990s, this return migration trend was dominated by males. It is likely that a non-negligible share of these migrants did not report their return to East Germany to the local registry authorities in West Germany. In addition, some of the errors observed among the cohorts born in the 1960s and the 1970s might have occurred as a result of the incorrect registration of international migration. In the early 1990s, there was a substantial wave of migration into Germany from Central-Eastern, South-Eastern, and Eastern Europe. It is very likely that some of these immigrants left Germany without reporting their departure (see also Statistisches Bundesamt 2016a), and that this under-reporting of out-migration contributed to the errors in the population estimates. In addition, errors can occur if the arrival of a migrant is recorded more than once. These double entries are particularly difficult to detect if the information about an individual migrant that is provided in these entries is not consistent.

\section{Data and Methodological Strategy}

In our adjustment, we mainly rely on official statistical data. ${ }^{9}$ Appropriate raw population and demographic events data must be available by sex. Since we favour a cohort-based approach, these data should ideally be stratified by both single year of age and birth year (i.e., in Lexis triangle format). Such an approach is preferable

9 The only exception to this general rule is the estimation of numbers for the former territories of East and West Berlin for the 2001-2011 period, for which we use population and demographic register data of the city of Berlin. 
to an age-based approach, as applying an age-based approach can be particularly problematic when adjacent cohorts differ substantially in size. Because of the effects of World War II and of temporal fertility fluctuations in (East and West) Germany in the subsequent decades, a number of successive cohorts in the German population vary substantially in size. For example, the cohort born in 1945 is much smaller than the cohort born in 1946. Thus, the deaths and the migration events that were registered for 55-year-olds in 2001 are more likely to be linked to the 1946 cohort than to the 1945 cohort.

In section 1 of the online appendix, we provide an overview of the data that we were able to obtain for the German states, East Germany, West Germany, and Germany as a whole. These data include the population estimates as of 31 December for the years 1987-2011, by sex and single year of age/birth year. ${ }^{10}$ For the whole inter-censal period, we have annual information on live births and deaths, with the latter being broken down by single year of age and birth year. As statistical data for East and West Berlin are only readily available for the period up to 2000, we include in the data for East and West Germany from 2001 onwards estimates for the two parts of the city that are based on the procedure described by Scholz et al. (2017). We also collected detailed migration data for each of the 16 federal states and for the sub-territories of Berlin, as we need these data to detect the corrections of the population statistics implemented in the German states in the years before the census. Information drawn from migration data is also used in some of the approaches we are considering for the adjustment of the inter-censal population estimates.

While we were able to obtain rich migration data for the $1991-2013$ period, ${ }^{11}$ there are some restrictions on the data we were able to collect. For example, we have to limit ourselves to using migration data that can be broken down by age and sex, but not by birth year, as we were unable to gain access to data that would allow us to use this information in a comprehensive manner for the whole age range. Overall, the level of data availability is slightly higher for international migration than for internal migration within Germany, as for most of the inter-censal period we were able to obtain data by single-year ages and sex (see online appendix, section 1). When looking at the internal migration data, we focus only on migration events across federal state borders, as it would have been very difficult - if not impossible to obtain information on migration events in which individuals did not cross federal state borders (by age and sex for East and West Germany) for the whole inter-censal period. ${ }^{12}$

Information on how the estimates on migration events for East and West Berlin were obtained is provided in section 2 of the online appendix. As we are considering some adjustment methods that require detailed migration data, it was our goal

$\overline{10}$ Based on HMD conventions, we treat these estimates as representing the population on 1 January of the successive year.

11 We also collected data for 2012 and 2013, as having time series that extend beyond the census of 2011 supports us in making our adjustments for prior cleaning.

12 Moves between East and West Berlin are not considered moves across federal state borders, as the two territories have been part of the same federal state since 1990. 
to obtain migration data by single-year ages at least up to ages $90+$. We had to deal with a number of challenges in the collection and the preparation of the data. For example, we only have access to data up to ages $75+$ for some years, and the internal migration data we could obtain for 1991-2000 are available for broad age groups only. The assumptions and procedures we used to derive estimates on migration by single-year ages are described in section 3 of the online appendix.

Another limitation is that we were unable to collect detailed internal and international migration data for East Germany for the 1988-1990 period. For this period, we use data on implied migration that we obtained by taking the differences between the official population estimates by single-year birth cohorts at year $t+1$ and year $t$, subtracting the registered births among the cohort born between $t$ and $t+1$, and adding the deaths by cohort. This process allowed us to derive the migration balance by cohort and sex. In East Germany during this period, out-migration levels were high and in-migration levels were low (Statistisches Bundesamt 1993). Hence, migration balances appear to represent a good approximation of external migration intensities. For internal migration, we were unable to obtain comprehensive data for East Germany for this period. Thus, we restrict ourselves to using the implied external migration balances for this period to derive information on migration intensities. As the description of the available migration data shows, our efforts to obtain detailed migration data for the first part of the inter-censal period met with only limited success. These challenges were among the main reasons why we ultimately decided to use for the HMD and the HFD an inter-censal adjustment approach that does not require migration data.

The deterministic adjustment methods we selected are in line with HMD and HFD standards. While we also had the option of using model-based approaches (see, e.g., Wheldon et al. 2016), we chose to use deterministic approaches instead because they are very transparent and can be limited to a small number of explicit assumptions. Model-based approaches allow for greater flexibility, but are usually based on a large number of explicit and implicit assumptions. If we were performing the inter-censal adjustment for one research project only, a model-based approach would probably have been the better choice, as we would have been able to ensure that the underlying assumptions of the implemented adjustments do not greatly affect the outcomes of the subsequent analyses for which the data are used. We are, however, performing this adjustment for international comparative databases. The adjusted population data might be employed for various purposes, and it would be unfortunate if the outcomes of future analyses of these data were driven primarily by assumptions that we used to implement the inter-censal adjustment. Background information on our adjustment methods is provided in the following sections 4 and 5 , and in the online appendix. 


\section{$4 \quad$ Adjustment for the official cleaning of the population statistics prior to the 2011 census}

\subsection{Considerations}

As we mentioned above, administrative authorities usually erase erroneous individual entries from the population statistics by assigning to them an out-migration abroad event. Among the main sources of these erroneous entries are the failure to register and the incorrect registration of international and internal migration events, as we described in section 2. For all time periods over the last inter-censal period, we observe temporal anomalies in the out-migration abroad trends for one or several years in one or several German states (see Fig. 2). The evidence of such anomalies provides support for the view that cleaning processes were implemented in different states at various times throughout the whole inter-censal period. We are less concerned about corrections made in the 1990s, as they occurred relatively close to the period in which the errors emerged. Therefore, we decided not to make any adjustments for cleaning processes in this period. We are, however, much more concerned about two periods in the 2000s when substantial corrections were made, as there are indications that these modifications may have been accounting for errors that emerged in the statistics in the late 1980s and the early 1990s. Thus, these modifications may have contributed to bias in the official population estimates for longer periods of time.

The first cleaning period we want to examine occurred in 2004. It appears that during this period, efforts were made to clean up erroneous entries in the German Central Register of Foreigners (Ausländerzentralregister), (Opfermann et al. 2006; Hannemann/Scholz 2009). While the main focus of this process was on making adjustments to this specific register, which is independent of the population statistics, the cross-checks with population register data likely resulted in the identification of erroneous cases that were then also taken into account in the production of the population estimates. However, the variation in anomalies across the states, which is visible in Figure 2, suggests that the extent of the cleaning undertaken varied considerably across the German states. According to Opfermann et al. (2006: 487), many foreigners who were identified in 2004 as no longer living in Germany had entered Germany during the 1986-1994 period. Since recently arrived foreigners are especially likely to make (potentially unregistered) moves within Germany or abroad (see also Constant/Massey 2003), many of these erroneous cases might have already emerged in this period through the under-registration of out-migration abroad events or the double registration of individuals due to incompletely reported internal migration events. If the cleaned cases in the population statistics are indeed related to the cleaning of the Central Register of Foreigners, they are likely to share these characteristics. Thus, the statistical offices have probably been accounting for bias that had affected the population estimates for a longer period of time. Another motivation for correcting the migration data for 2004 is that the West German state of Hesse reported for that year large anomalies in the statistics for migration 


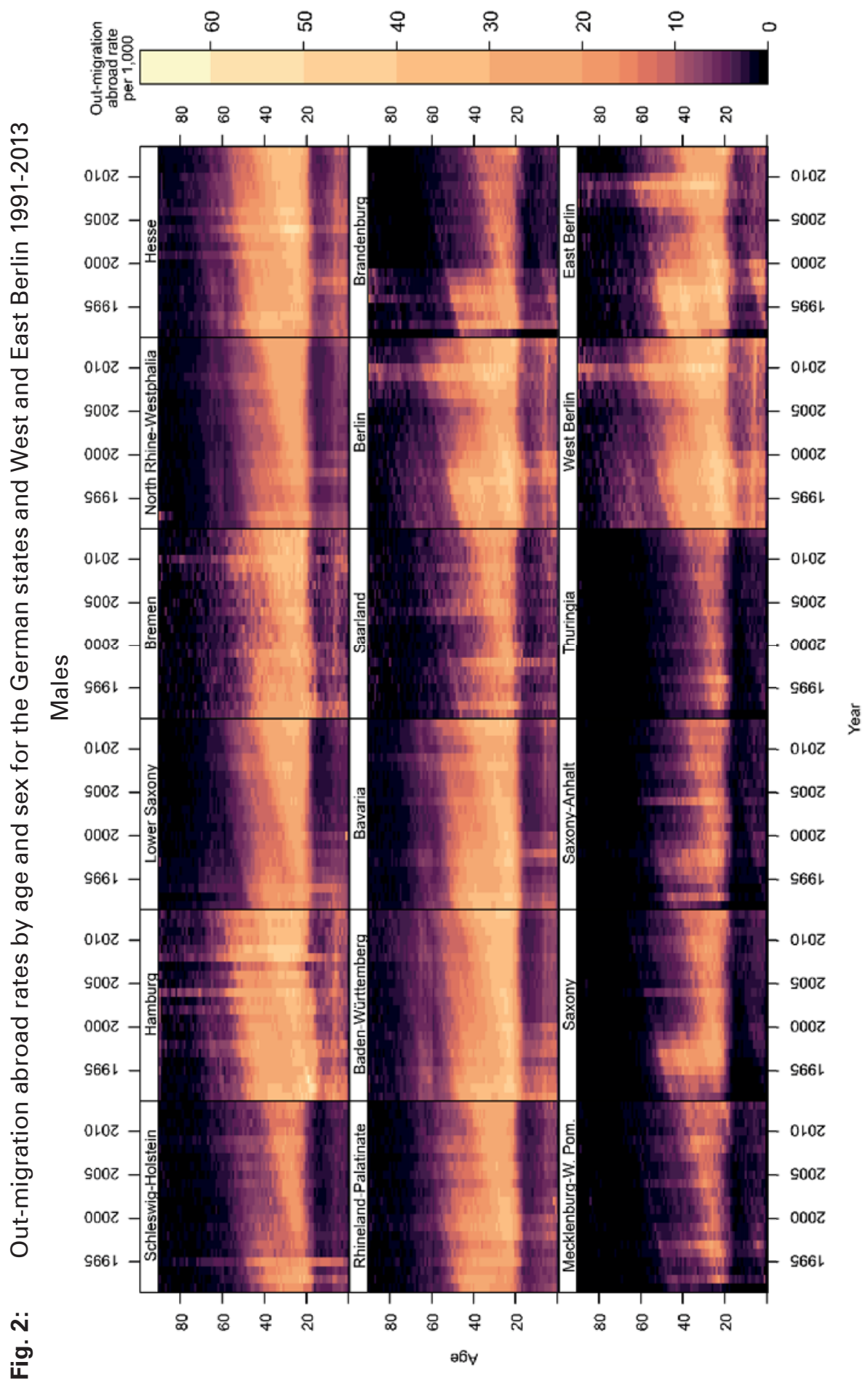




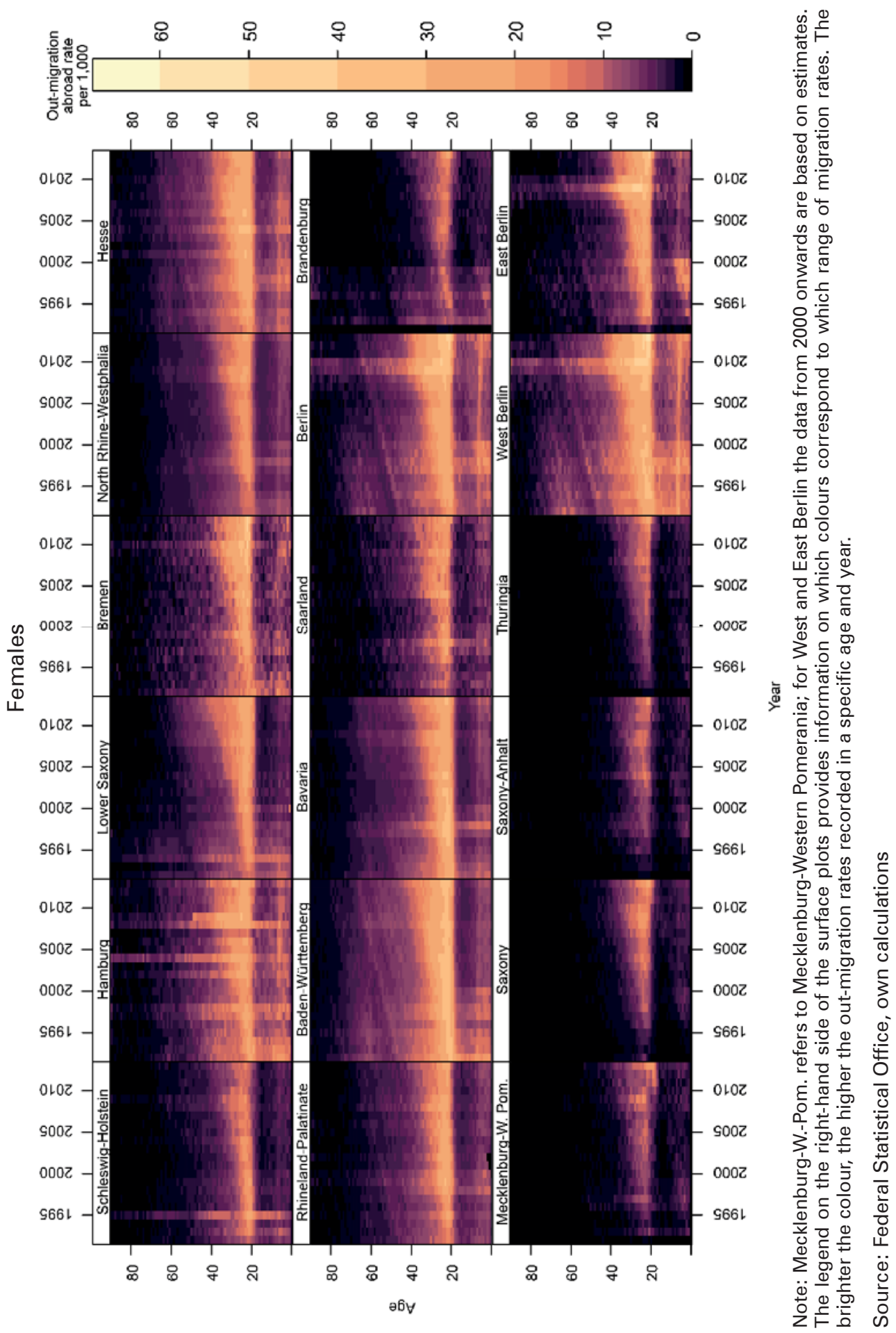


both to and from other countries. These anomalies seem to be largely an artefact of the over-registration of external and internal migration moves among Germans (see Statistisches Bundesamt 2014: 10). ${ }^{13}$

The second cleaning period is related to the introduction of a unified tax identification number starting in mid-2007 (see also Ette/Sauer 2010; Scholz/Kreyenfeld 2016). In order to limit the number of cases in which a person who had registered her or his main residence in two places was issued two identification numbers, efforts were made to identify and eliminate double entries in the registers. According to the Federal Statistical Office, the cleaning of the registers in response to the introduction of the tax identification number affected the published population statistics in the years 2008-2010 (Statistisches Bundesamt 2014: 10). This statement is in line with the results of our empirical inspections, which identified a clustering of un-usual positive anomalies in these three years in the out-migration abroad trends in many German states. Such anomalies are detectable up to high ages, even though out-migration abroad intensities are generally very low among the elderly (see Fig. 2).

Therefore, in our attempt to account for prior-cleaning efforts, we chose to focus on the year 2004 and the 2008-2010 period. As we noted above, in most instances the artificial migration events that were entered as part of the cleaning process cannot be distinguished from real international migration events, even using the individual-level migration register data to which we have access through the German Research Data Centres (FDZ 2014). We thus have to derive estimates of the extent of the cleaning that was undertaken in a given period from observed irregularities in the out-migration abroad trends. In using this approach, we benefit from the relative stability of out-migration abroad trends. In rare cases, state statistical offices integrated an identifier into the individual-level migration statistics that makes it easier to distinguish between artificial and real migration events. Such an identifier was, for example, used by the state of Hesse in adjusting its population estimates in $2004 .^{14}$ These rare cases provide us with an opportunity to explore the reliability of our estimation approach.

We decided to implement our adjustments of the corrections at the level of the 16 German states, with the state of Berlin being further subdivided into East and West Berlin. Our choice was made for two main reasons. The first reason is that the timing and the intensity of the corrections vary across the German states. The second reason is that this approach has an "additive" feature. In an approach in

13 While in the first decade of the $21^{\text {st }}$ century Hesse registered around $85,000-90,000$ international out-migration abroad events and around 85,000-98,000 in-migration events from foreign countries, the respective numbers for 2004 were 118,000 and 112,000.

14 In this case, Hesse marked cleaned entries as out-migration events to unknown destinations abroad, and registered them in December 2004. We cannot rule out the possibility that some of these events are not related to the cleaning, but a comparison of these events with out-migration events to unknown destinations in the preceding and the successive months reassures us that the share cannot be much higher than 25 percent, and that it is likely to be much lower than 25 percent. 
which we adjusted the numbers separately for Germany as a whole as well as for East and West Germany, the numbers for East and West Germany would not add up to the numbers derived for Germany as a whole. These inconsistencies can be circumvented in our approach, in which we implement this adjustment for the subterritories and then derive the outcomes for the higher-level units by summing up the values of their lower-level sub-units. In order to implement the corrections for the cohorts, we derive estimates of migration events by single birth cohorts by splitting the migration data by age. This splitting procedure is based on the assumption that the period migration rates were constant across the two successive birth cohorts that contributed the migration events of a specific age in a given year (e.g., the migration rates of the cohorts born in 1974 and 1975 who contributed migration events at age 20 in 1995). ${ }^{15}$ This implies that the splitting procedure is based on differences in cohort size only. Formulas for this procedure are provided in section 4 of the online appendix. It should be noted that this splitting procedure has implications for the top open-age category, as cohort proportions in specific ages can only be derived up to one age below the top open-age category, because we lack information on the older cohort at the end of the year. Thus, we can derive cohort proportions only up to age 88 . Due to the splitting of migration events into Lexis triangles, the open-age category changes from $90+$ (the last age group for whom the raw data are available) to $89+$.

Our adjustment for corrections prior to the census is based on the assumption that in those years in which corrections were implemented (2004, 2008-2010), all positive anomalies (i.e., sudden spikes) from time trends in external out-migration rates by cohort are due to corrections implemented by the statistical offices. We restrict ourselves to positive anomalies, as corrections made by the statistical offices can increase, but cannot decrease the external migration rates. With the estimated cohort migration rates, we are able to implement this adjustment in a cohort-wise manner. Thus, our focus is on the migration trends among cohorts who reached a specific age in a given year (e.g., 35) over the 1991-2013 period.

In order to estimate the artificial migration events in the years 2004 and 20082010 , we use the following procedure. First, we derive the observed migration rates. We then remove the observed rates for the years 2004 and 2008-2010. The removed data points are treated as "missing" values to be interpolated on the basis of the remaining data points (1991-2003, 2005-2007, and 2011-2013). Second, we interpolate these missing points using a piecewise cubic Hermite interpolation spline (function interp1 from R package signal; see also Fritsch/Carlson 1980). The obtained values represent the "expected" migration rates. Next, in those cases in which the "expected" migration rates are lower than the observed rates (i.e., in which we see

15 This assumption holds true for most of the life course, and is perhaps only problematic for ages $18-20$, as migration rates increase substantially immediately after graduation from secondary school. However, even in these cases we believe the distortion is rather small, as the individuals who make up a school cohort are derived from births that took place between the summer of a given year and the summer of the successive year (exact dates vary across German states). Hence, a cohort of school leavers is comprised of individuals from at least two birth cohorts. 
Fig. 3: Graphical representation of selected outcomes of the Hermite spline interpolation

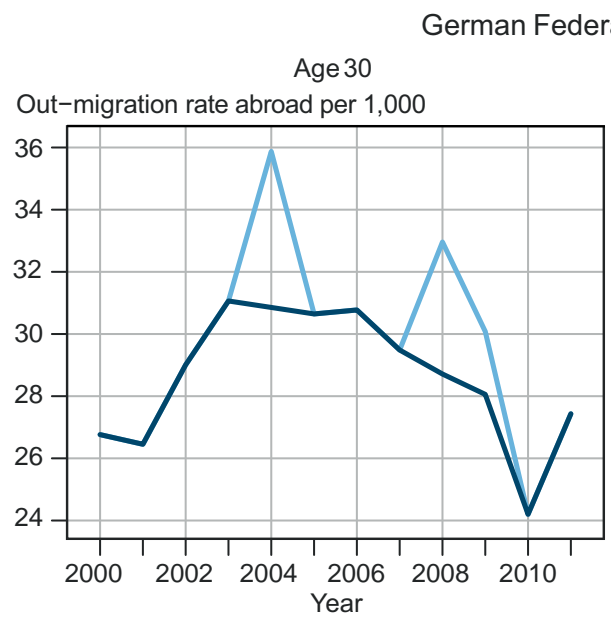

Age 65

Out-migration rate abroad per 1,000

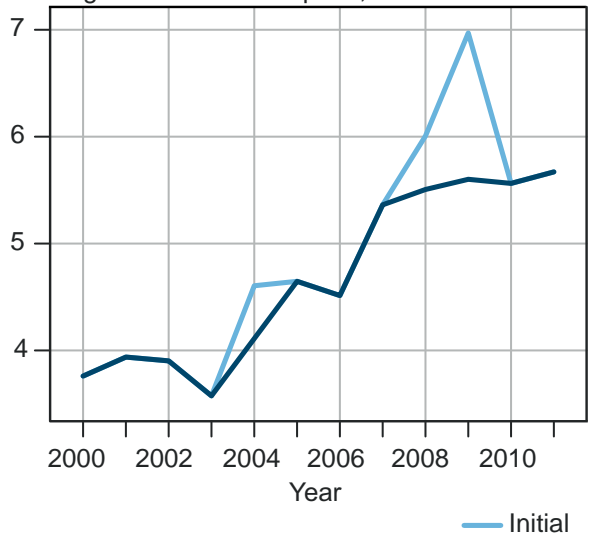

Age 50

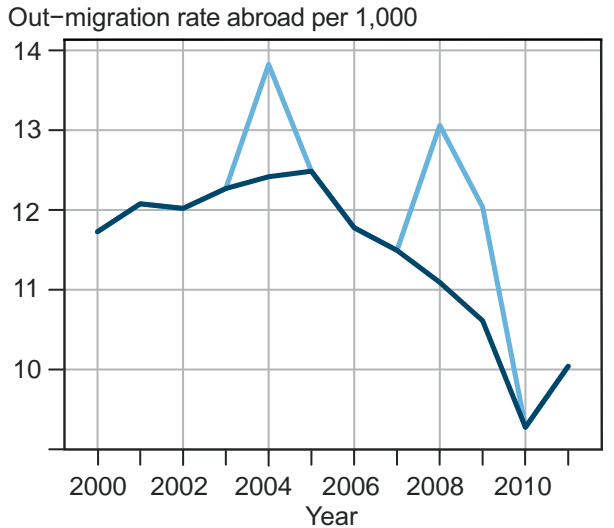

Age 75

Out-migration rate abroad per 1,000

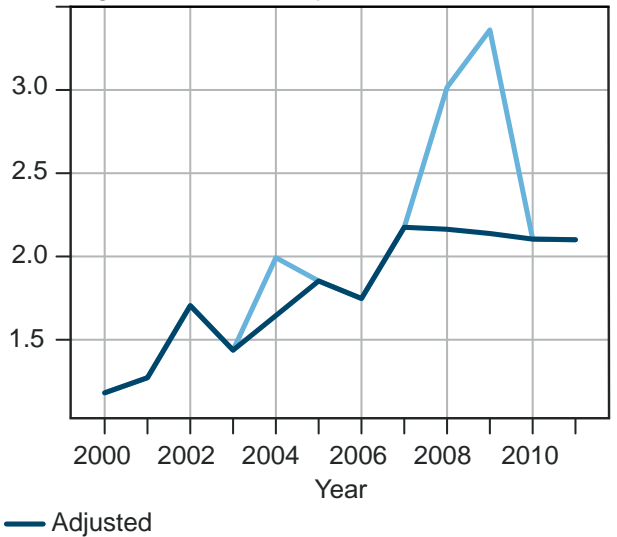

Note: These plots, which are based on data for Bavaria, demonstrate our approach to estimating the scale of the corrections implemented in the population statistics in the years prior to the 2011 census. We focus on the years 2004 and 2008-2010, which we identified as years with substantial corrections. Once detected, an erroneous case is typically removed from the official statistics by assigning an out-migration abroad event to it. If, however, the erroneous case did not stem from an unregistered out-migration event in the same year, this practice can increase the risk of artificially inflating the out-migration abroad statistics. With the Hermite spline interpolation, we derive for the years with intensive cleaning estimates of the out-migration rates that would have been registered if no corrections had been implemented in these years. This interpolation uses information from the trends in out-migration rates by the age reached at the end of the year in the years without substantial cleaning Each subplot displays the initial and the adjusted out-migration abroad rates for cohorts that reached a specific age in a given year. For example, the plot for age 30 shows the initial and the adjusted outmigration rates for cohorts who reached age 30 in a specific year (e.g., 1970 in 2000, 1971 in 2001). The initial and the adjusted data only deviate in the years for which we applied the Hermite spline interpolation to adjust for cleaning. The plots show that in the years 2004 and 2008-2010, there are indeed frequent anomalies that are quite well captured using the Hermite spline approach.

Source: Federal Statistical Office, own calculations 
Fig. 4: Hermite spline estimate of cleaned cases vs. an estimate based on an identifier in migration register data

German Federal State of Hesse

Out-migration abroad
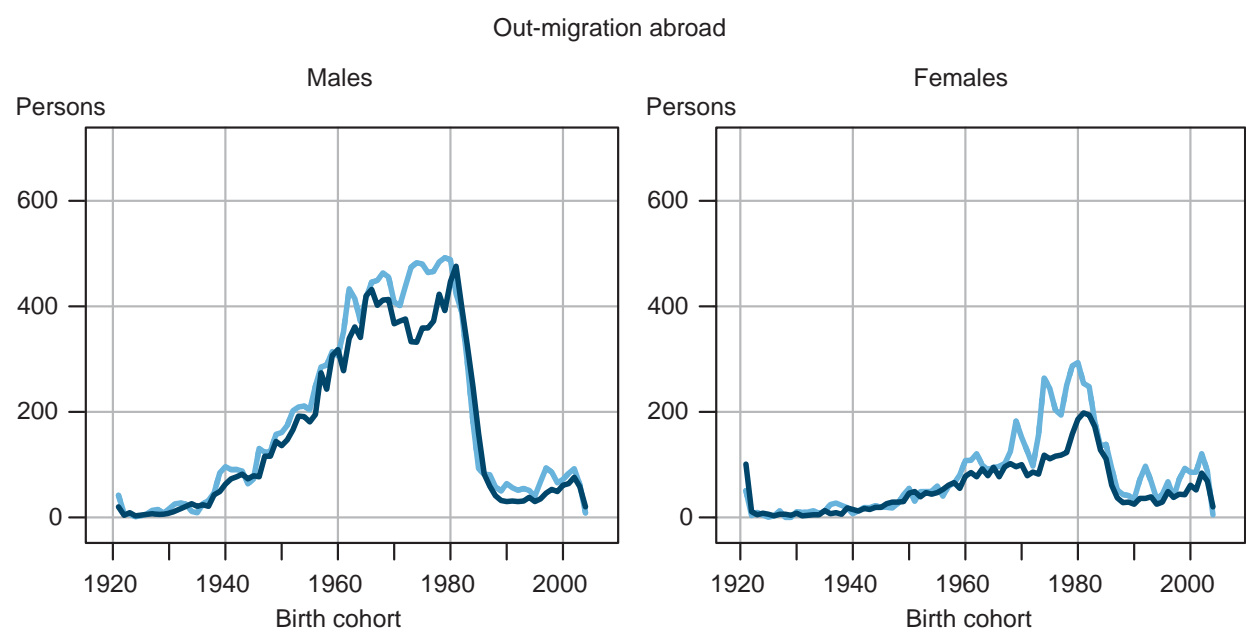

Spline estimate

— Official statistics

Note: This graph provides a consistency check for our estimates of cleaned cases as part of the priorcleaning adjustment approach. For Hesse in 2004, we are able to derive a relatively accurate estimate of the officially cleaned cases through an identifier available in the individual-level migration register data. This figure compares the birth cohort structure of the estimate of the cleaned cases derived from the migration register data (Official statistics) with the estimated cleaned cases obtained with the Hermite spline approach (Spline estimate).

Source: Federal Statistical Office, FDZ (2014), own calculations

a positive anomaly), we subtract the former from the latter rates to determine the "excessive" migration rates. These rates are then transformed into our estimates of "artificial" migration events due to corrections. Finally, we check the plausibility of the obtained results by means of a visual examination of the trends. A graphical representation of this approach is shown in Figure $3 .^{16}$

16 An additional challenge we faced was an inconsistency in the external migration statistics of the German state of Hamburg for 2007 and 2008. Around 7,000 migration events to unknown destinations abroad that occurred in 2007 were erroneously recorded in the statistics for 2008. This constituted a problem in our attempt to identify artificial out-migration events in the cleaning year of 2008 using a spline method, as the misreported cases lowered the 2007 migration statistics and inflated the 2008 numbers. We thus apply a two-step procedure for Hamburg. In the first step, we perform a spline estimation in which we exclude next to the data for 2004 and 2008-2010 also the data for 2007 to derive an estimate of the extent to which the recorded migration events for 2007 deviate from the trend. Using this technique, we identified 6,968 cases broken down by cohort and sex; a number that is close to the 7,000 delayed registered cases reported in official statistical publications. These cases are deducted from the Hamburg migration statistics for 2008 and added to the statistics for 2007. In addition, we adapt the population estimates for Hamburg for 1 January 2008 to account for the migration moves that we shift from 2008 back to 2007, which result in slightly smaller population numbers at the beginning of 2008 . In the second step, we implement for Hamburg the same procedure used for the other states to derive estimates for 2004 and 2008-2010. 
For Hesse, we also need (for the reasons outlined above) to apply this procedure to the 2004 statistics on in-migration from foreign countries. This approach is based on the same principles as those we follow in the adjustment of the out-migration statistics. We deduct for Hesse the estimated in-migration event artefacts from the estimated out-migration event artefacts. Cases in which we obtain negative numbers for specific outcomes by cohort and sex are set to zero, as it is unlikely that the cleaning of the population statistics would have created additional person entries in the population statistics. We verify the validity of our approach by comparing our estimates with the generally reliable estimates derived from official information on cleaned cases by cohort in 2004 for the state of Hesse. The outcomes shown in Figure 4 suggest that our estimation method works reasonably well.

\subsection{Outcomes of the adjustment for prior cleaning}

Our estimates in the adjustment for prior cleaning suggest that around 145,000 male cases and 117,000 female cases were removed from the official statistics in the years 2004 and 2008-2010. Broken down by region, we identified with our estimates 114,000 male cases and 98,000 female cases in West Germany, and 31,000 male cases and 18,000 female cases in East Germany. If we add these cases to the accumulated error, ${ }^{17}$ the shares for Germany as a whole increase from 2.5 percent to 2.9 percent for males and from 1.3 percent to 1.6 percent for females (for the percentage deviations, we take the estimates based on the officially corrected 2011 census data as a reference). In Figure 1 (page 38), we plot the cohort distribution of the cases that were identified. We can see that the prior cleaning was particularly intense among the cohorts who were aged 25-40 in 2011 (see dark blue bars). Generally, when we adjust for prior cleaning we seem to get a more meaningful deviation pattern in the accumulated error by cohort for the population under age 60 at the end of the inter-censal period (stacked blue and dark blue bars). While the deviations between the population estimates as of 1 January 2012 that are based on the old and the new censuses (denoted by the blue bars) often have a bimodal shape, with humps at ages in the twenties and the forties; the shapes we obtain after accounting for the corrections appear to be closer to a unimodal distribution of the accumulated error. We consider this pattern to be more meaningful, as it is likely that the accumulation and the elimination of errors vary systematically across the life course. While the registration of these cohorts by the state authorities is highly accurate during their school years, errors start to increase when the cohorts become young adults, and thus are leaving home. It is likely that some of these errors can be detected and eliminated as the cohorts grow older, and thus reach ages at which migration intensities tend to be lower.

17 Which we defined above as the difference between the population estimates on 1 January 2012 based on the old censuses and the new census. 


\section{Testing approaches to adjust the inter-censal population estimates}

\subsection{Considerations}

While the prior-cleaning adjustment in section 4 dealt with a specificity of the German case, we turn now to the evaluation of four adjustment strategies. The four approaches considered differ in their underlying assumptions and data requirements. All of the adjustments are carried out separately by sex and region (East, West, and total Germany). As the initial population, we take the population on 1 January 1988. We split the open-age category $90+$ of this population into data by single-year ages using the survivor ratio method of the HMD (see Wilmoth et al. 2007). As population at the end of the inter-censal period, we employ the official population estimates as of 1 January 2012 based on the officially corrected 2011 census outcomes. As these data are available up to ages $100+$, we again use the survivor ratio method to split the data at ages $100+$ into single-year ages. In the following, we will refer to these population numbers as population estimates based on the 2011 census.

The first approach is the standard HMD methodology for cases in which population estimates between two censuses are either not available or not reliable (Wilmoth et al. 2007). This method, which we refer to as the basic approach, is based on the assumption that the only reliable population data collected outside of the census are data on births and deaths. Migration data are not taken into account, as they are either not available or are considered insufficiently reliable. The basic approach assumes that migration balances are constant over the inter-censal period, and that the accumulated error detected at the end of the inter-censal period has accrued uniformly over time. However, as it appears that the assumption of constant migration balances is violated in the German case, we expect that the direct application of the basic approach will not yield satisfactory results. Nevertheless, we present this method here, as it serves as the basis for developing alternative approaches more appropriate for the German case. In this first approach, we start with the base population at the beginning of the inter-censal period, and estimate the population size incrementally forward over the years by adding births and subtracting deaths in a cohort-wise manner. We then derive for the end of the inter-censal period the accumulated deviation by cohort by obtaining for each cohort the difference between our calculated numbers and the population estimates based on the 2011 census. ${ }^{18}$ The derived deviation by cohort - which is attributable to unbalanced migration and errors in the statistics - is then assumed to have accumulated uniformly over the inter-censal years, and is added to our incrementally derived population estimates by cohort. A formal description of this method is provided in section 5 of the online appendix.

The second approach, the migration-adjusted approach, takes into account variation in migration event occurrences, simultaneously across cohorts and time. Unlike in the basic approach, in this approach we relax our assumptions about data

18 For this approach, the prior-cleaning adjustment has no effect, as we do not make use of any migration data and population estimates that were published in the inter-censal period. 
reliability, and assume that in-migration events ${ }^{19}$ (both across national borders and across federal state borders within Germany) are adequately measured, and thus can be used for the incremental forward calculation of the population estimates. The only numbers we consider unreliable are those related to out-migration events both across national borders and across federal state borders within Germany. As mentioned above, the under-registration of out-migration represents the biggest challenge in deriving migration statistics. Nevertheless, we believe that the outmigration data still provide meaningful information on variation in the occurrence of out-migration events over time. We assume in this approach that this registered variation affected the accumulation of errors in the inter-censal population estimates by cohort over time. In other words, in the sub-periods of the inter-censal period in which a cohort had an above-average number of registered out-migration events, we assume that the cohort also experienced a similar above-average contribution to the accumulated deviation, which we detect for this cohort at the end of the period between our forward-calculated prior-cleaning-adjusted population estimates and the population estimates based on the 2011 census.

We decided to use the migration events instead of the intensities, as we consider the events more appropriate when seeking to account for the accumulation of errors in cohorts that are subject to big changes in size over time (either due to deaths or due to migration). If, for example, the population size of a cohort shrinks - predominantly due to deaths - from 10,000 to 1,000, while the cohort's migration intensities stay the same, we would assume based on the intensities that the same absolute amount of error accumulated in the cohort in a year at the beginning and in a year at the end of the period of years in which the cohort experienced this drastic decrease. However, we consider it more realistic to assume that in the initial years, the total accumulation of error was greater as the cohort was bigger. This aspect is better reflected in the migration event numbers. We will thus redistribute the error proportionally by cohort based on the out-migration events a cohort experienced in a given year relative to the other years of the inter-censal period (for more details see section 5 of the online appendix). As in the prior-cleaning adjustment, we follow a cohort-based approach. This implies that we needed to split the prior-cleaning-adjusted migration events again into Lexis triangles following the equations described in section 4 of the online appendix, this time using the prior-cleaning-adjusted population numbers as a reference. By applying the splitting procedure a second time, the top open-age category is further reduced to 88+. Migration events at ages 88+ are not taken into account in this second approach, as doing so would have made it necessary to generate an estimate of the distribution of migration events across single-year ages in this $88+$ category. Since the number of migration events in this category is rather small, we decided not to introduce additional assumptions about how the migration events might be distributed in the open-age category. Instead, we assume no (selective) migration at ages $88+$.

${ }^{19}$ We deduct from the migration data the migration events that our prior-cleaning adjustment estimations identified as artefacts resulting from the data cleaning. 
While it might be appropriate in general to believe that accumulated errors detected at the end of the inter-censal period emerged proportionally to temporal variation in out-migration events over the inter-censal period, this assumption does not necessarily apply to all cohorts. If, for example, we consider the cohorts born in the late 1980s in East Germany, we see that they experienced above-average numbers of migration events around 1990, when many of them moved with their parents to West Germany. However, erroneous entries of small children in the population registers are usually detected when they reach the age at which they have to enter school. Thus, it is less likely for these cohorts than it is for older cohorts that the errors which emerged in the early 1990s persisted up to the 2011 census. Another limitation of this approach is the lack of detailed migration data for parts of the intercensal period. For example, we have very limited information for East Germany for the 1980s. Moreover, because the data on internal migration between 1991 and 1999 are provided in broad age categories only, we had to split the data into singleyear ages on the basis of detailed migration data available for Germany as a whole. These data availability constraints motivated us to develop a third simplified approach that takes migration information into account, but has less demanding data requirements.

In this third strategy, which we refer to as the simplified migration-adjusted approach, we consider both variation in total migration intensities over time and variation in migration intensities by age. The latter information we obtain from a reference year in the middle of the inter-censal period. In our case, the reference year is 2000 , for which we have available migration data by single-year ages. Another difference between the third approach and the second approach is that for the third we decided to reduce complexity by considering in- and out-migration events equally reliable. This implies that for the simplified migration-adjusted approach (as well as for our fourth approach), we do not need to obtain our own population estimates for the inter-censal estimates, but can instead use the officially published population estimates that the German statistical offices derived based on registered births, deaths, and in- and out-migration events. The population estimates and migration counts have, however, been adjusted by us for prior cleaning. A special case is that of the population numbers by single-year ages for the prior-cleaning-adjusted population at ages $88+$, for whom we cannot rely on official population numbers. If a cohort reaches the age of 87, we move to an incremental forward calculation in which we are subtracting the death events that are recorded for this cohort in a specific year. Migration events are not taken into account, which implies that we again assume no selective migration above age 87 . At the end of the inter-censal period we then derive the accumulated deviation from the officially corrected population estimates based on the 2011 census.

The information on variation in migration intensities by age in our reference year is obtained in a cohort-wise manner (i.e., age reached during the year). These calculations are based on the migration data by cohort up to ages 87 , which we already used for the second approach. This implies that also in this third approach for the redistribution of the accumulated error by age, migration at ages $88+$ is not considered. In order to derive information on how to redistribute the accrual of the 
prior-cleaning-adjusted accumulated error over the years of the inter-censal period across cohorts, we use migration intensities for the total population independent of age. Both the migration intensities by age and by year comprise external and internal in- and out-migration events. However, as in the second approach, for the information on variation by age we will not use the intensities, as they would not account for the fact that cohort sizes can change substantially over time (particularly at older ages). Thus, we transfer for each year our year-2000 migration intensity data by the age reached at the end of the year (i.e., cohort) back into migration events, while taking the cohort size in a specific year into account (derived as the mean of the cohort size at the beginning and the end of a year). Next, we derive separately for the migration intensities by year and for the migration counts by age (at the end of the year) and year matrices with proportional data for each cohort. We then add these two matrices with proportional data and divide them by two. ${ }^{20}$ The resulting weights are then used to redistribute the accrual of the detected prior-cleaningadjusted accumulated error (see section 5 of the online appendix for details).

The fourth approach, the so-called population-size-adjusted approach, is much less data-demanding than the second and the third approaches, which require migration data. For this approach, we assume that the accumulated error by cohort (as well as by sex and region) is simply dependent on the changes in the population size of cohorts over time. As we do not depend on migration data when using this approach, we do not need to again derive the estimates on migration events by cohort after the prior-cleaning adjustment. This implies that we can work with population data up to ages $89+$ instead of up to ages $88+$. We use the official population estimates and our own forward-calculated population estimates at ages $89+$, which we obtain in a manner similar to that applied in the third approach. The prior-cleaningadjusted error is then, like in the third approach, derived by comparing the population estimates based on the 2011 census, with the population estimates based on the 1981 and 1987 censuses, which are forward-calculated at ages 89+. To obtain the weights according to which the detected error has accrued, we use information how the population size of each cohort (derived as the mean of the cohort size at the beginning and the end of a year) varied over the inter-censal period. As we prefer this approach to be additive across geographic hierarchies, we decided not to calculate these proportional weights for East, West, and total Germany separately. Instead, we derive the weights for total Germany (separately by sex), and then apply these weights to East and West Germany as well. ${ }^{21}$ We believe that this restriction is acceptable, as the population-size weighting is mostly accounting for newly born cohorts in the first year and the changes in the older cohorts, among whom the number of deaths is high. As there is limited regional variation in the steepness of

20 It is in principle also possible to give the age and the year information different degrees of significance in deriving the weights.

21 This approach was also applied in deriving the adjusted population numbers for the 16 German states and East and West Berlin, which are presented in the online data appendix. 
the increases in mortality risks over age within Germany, we believe that it is justified to use the weights for Germany as a whole for the German sub-territories as well (see section 5 of the online appendix for details).

\subsection{Outcomes}

In presenting the outcomes for the four different approaches, we will first contrast the official population estimates with the estimated adjusted development of the total population of Germany by sex (Fig. 5). As expected, we find that in this case the application of the basic approach does not yield plausible results. The outcomes for the other three approaches differ only marginally at the level of the total population. For the total population, we can also compare our numbers with the official adjustment published by the Federal Statistical Office. The trends in the two sets of figures are very similar, which is reassuring. However, we see slight differences in the levels, as our numbers are lower than the officially adjusted numbers for most of the inter-censal period. These differences seem to be mostly attributable to our decision to start the inter-censal period on 1 January 1988, while the official adjustment does not start until 31 December 1990 (see the conclusion for more details).

As our approaches two to four produce very similar results at the population level, we decided to take the fourth population-size-adjusted approach into more serious consideration as our potential final choice, as it is the leanest strategy in terms of data demand. A big advantage of this approach is that it is not dependent on the availability of detailed migration data, which we had estimated for the 1980s and the 1990s based in part on some rather bold assumptions. Another advantage of the population-size-adjusted approach relative to the other three approaches is that the outcomes at different hierarchies are additive. This implies that if we implement the adjustment for East and West Germany separately and add the resulting numbers to derive the total numbers for Germany, we obtain the same numbers as we would have if we had applied the adjustment directly to the data for Germany as a whole.

However, while differences between the second, third, and fourth approaches might be marginal at the level of the total population, there could still be strong deviations for specific cohorts. We thus explored how the adjusted population estimates that are derived using the fourth population-size-adjusted approach differ from the estimates that are obtained by applying the second migration-adjusted approach, in which we consider variation in migration over time by cohort, sex, and region (for East and West Germany, and for Germany as a whole). This comparison is displayed in Figure 6, which focuses on the ages for which we have access to migration data by single-year ages (up to age 87). The figure shows the deviations of the adjusted population numbers obtained using the second approach from the numbers derived by applying our favoured fourth approach (in percent). The biggest deviations are visible in East Germany, where there was substantial outmigration, mostly to West Germany. The deviations are greatest among the cohorts born between 1950 and 1990, and are especially large in the late 1990s and the early 2000s. For the cohorts born between 1950 and 1970, the migration-adjusted approach provides lower estimates than the population-size-adjusted approach, as 
Fig. 5: $\quad$ Development of total population 1 January 1988 - 1 January 2014 (official vs. adjusted numbers)

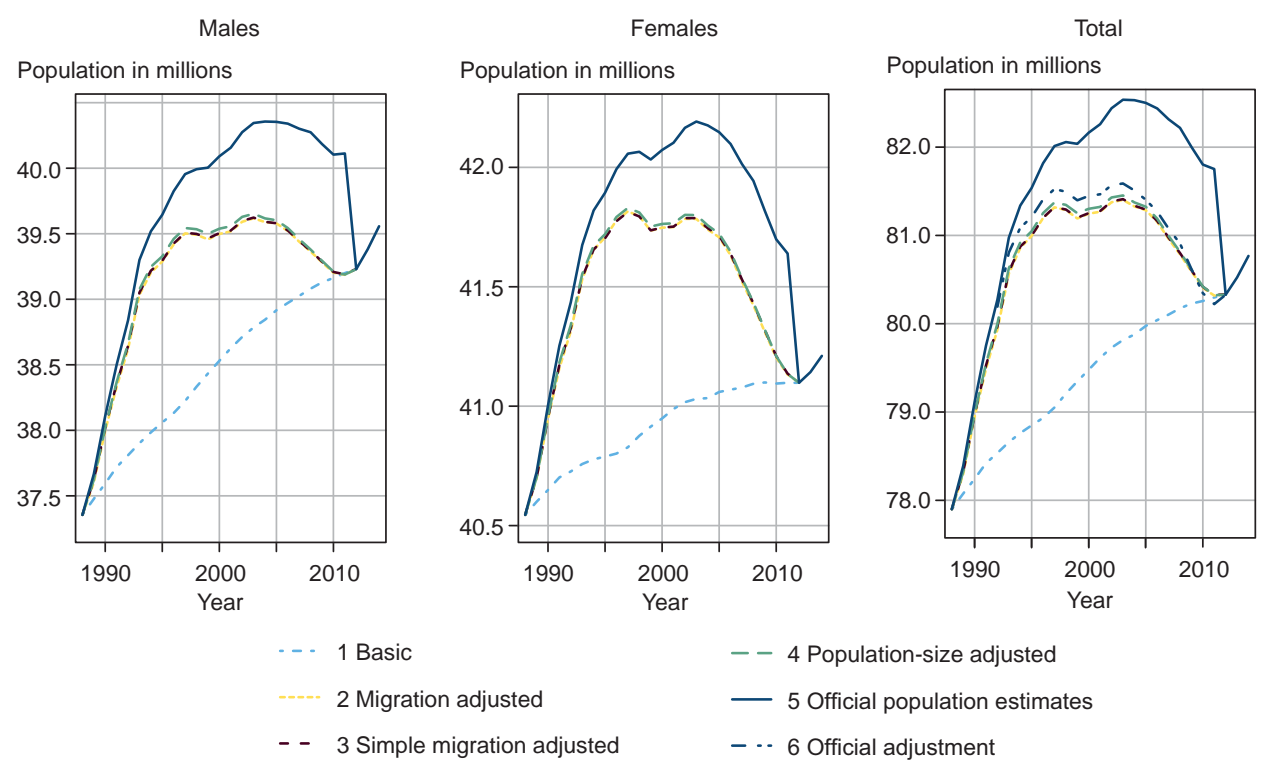

Note: Lines one to four represent the resulting adjusted population estimates based on our four approaches, while line five shows the initially published population estimates. For the graph for the total population on the right, we are also able to add the population development estimates based on the official inter-censal adjustment implemented by the Federal Statistical Office (line six).

Source: Federal Statistical Office, own calculations

the latter does not account for the high migration intensities among these cohorts around 1990. For the cohorts born between 1970 and 1990, the migration-adjusted approach results in higher numbers than the population-size-adjusted approach because the latter does not take into account that these East German cohorts did not enter ages with particularly high migration intensities until the 2000s. However, the deviations are not large. If we consider in combination any time and age/cohort up to age 87 for the six populations (women and men in East and West Germany, and Germany as a whole) for the years between the censuses (1988-2010), we obtain a mean of -0.05 percent and a standard deviation of 0.62 percent. We detect deviations bigger than 5 percent in 30 cases only, with the largest deviation being 7.6 percent. These elevated deviations above 5 percent are solely concentrated among East German females at ages 18-23 in the 1990s. The rather small overall deviations reassure us that the population-size-adjusted approach is an appropriate choice. ${ }^{22}$

22 The differences between the adjusted population estimates derived using the simplified migration-adjusted approach and the migration-adjusted approach are even smaller, but we still prefer to use the population-size-adjusted approach, as it does not rely on migration data that we estimated based on some rather bold assumptions. 
Fig. 6: Comparison of adjusted population estimates: Deviation of migrationadjusted numbers from population-size-adjusted numbers in \%

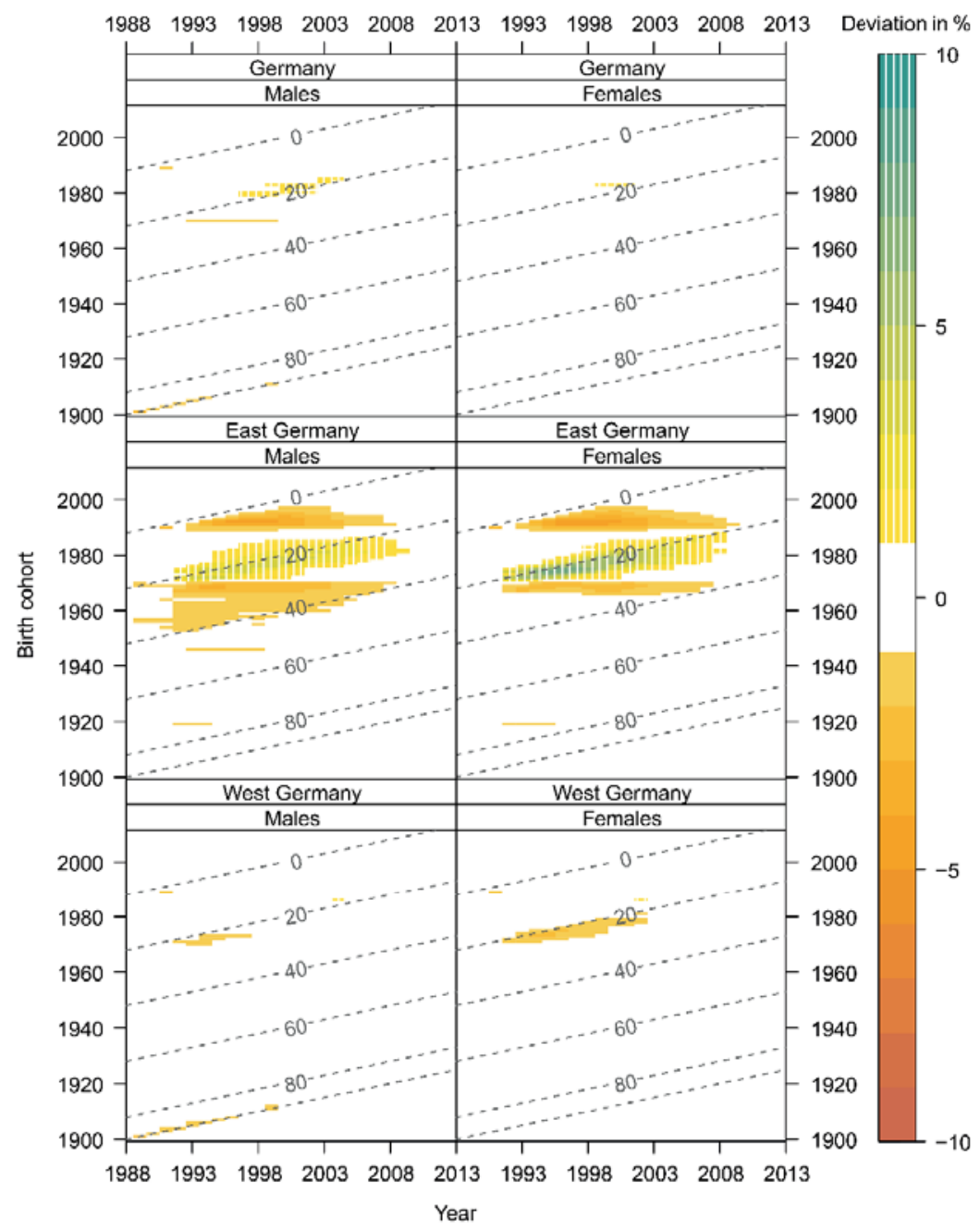

Note: The figure shows the deviation of the adjusted population estimates derived using the migration-adjusted approach from those obtained through the population-size-adjusted approach, with the latter serving as the point of reference (in percent). The legend on the right-hand side depicts which deviations in percent correspond to which colours in the surface plot. Deviations are shown for 1 January of a given year. The dotted grey diagonal lines denote the ages that the birth cohorts depicted on the $y$-axis reached in specific years (the 1980 cohort, for example, turned 20 in 2000). If the deviation is negative/positive, the migration-adjusted approach derives lower/higher adjusted population numbers than the population-size-adjusted approach. In East Germany, for example, the migration-adjusted approach returns higher population numbers for cohorts born between 1975 and 1985 through most of the 1990s. Unlike the population-size-adjusted approach, this approach takes into account that these cohorts did not reach ages with high migration intensities until later in the inter-censal period. Thus, the migration-adjusted approach assumes that most of the positive error detected in the census accrued in this later period, and applies fewer deductions to the population estimates in the first part of the inter-censal period.

Source: Federal Statistical Office, own calculations 


\section{Effects of the adjustment of inter-censal population estimates on mortality measures}

To assess the impact of our chosen adjustment of inter-censal population estimates on mortality indicators, we compare our newly derived life expectancy estimates for Germany ${ }^{23}$ with estimates from other sources (Fig. 7). For this comparison, we use data obtained from the Federal Statistical Office of Germany (FSO), the WHO, Eurostat, and previously published HMD data. ${ }^{24}$ As these sources provide data for Germany as a whole since 1990 only, we focus on the 1990-2011 period. With the exception of the data from the FSO, which publishes three-year averages, all of the other sources provide annual numbers. For our comparison, the data for the FSO are centred on the middle of a three-year period.

According to our adjusted numbers, the life expectancy at birth $\left(e_{0}\right)$ of males increased between 1990 and 2011 from 71.9 to 77.8 years. At the end of the intercensal period, when the accumulated error was highest, this figure was around 0.2 years lower than the corresponding figures provided by the FSO and the old HMD estimates. Compared to the numbers cited in international databases, such as the Health for All database of the WHO and the Eurostat database, we detect a substantial negative deviation of up to 0.6 years. For females, our adjusted calculations show that the $e_{0}$ increased from 78.4 to 82.8 years between 1990 and 2011. The deviations from the numbers provided in other databases are somewhat smaller in this case because of the lower levels of accumulated error among females. At the end of the inter-censal period, our adjusted numbers are around 0.1 years lower than the numbers from the FSO and our previously published numbers. The data on the female $e_{0}$ provided by the WHO and Eurostat seem to suffer from some deficiencies, as they exhibit unreasonable fluctuations in the period between 2000 and 2006. In the period around 2010, our adjusted numbers are up to 0.45 years lower than the female $e_{0}$ obtained from the WHO and Eurostat. This gap is also not insubstantial.

In the two lower plots of Figure 7, we can see the effects of the adjustment on life expectancies at age 90. We were unable to obtain data from the WHO and Eurostat for this age. The comparison with the previously published HMD data provides support for the view that our pension adjustment factor generally performed well in tracking the development of life expectancy at high ages. However, among males from 2005 onwards, we find an increasing negative deviation that amounts to around 0.2 years in 2010. The FSO numbers also show a negative deviation for males from our adjusted numbers of the same magnitude; again, of around 0.2 years. The similarities between the FSO numbers and our numbers suggest that the FSO also implemented adjustments to account for known deficiencies in the intercensal population estimates.

23 Based on HMD methodology.

24 In preparing the previously published HMD numbers, the population at high ages had been adjusted based on information from German pension data (Scholz/Jdanov 2007). 
Fig. 7: Deviation of the life expectancies based on our adjusted inter-censal population data from the life expectancies from other sources
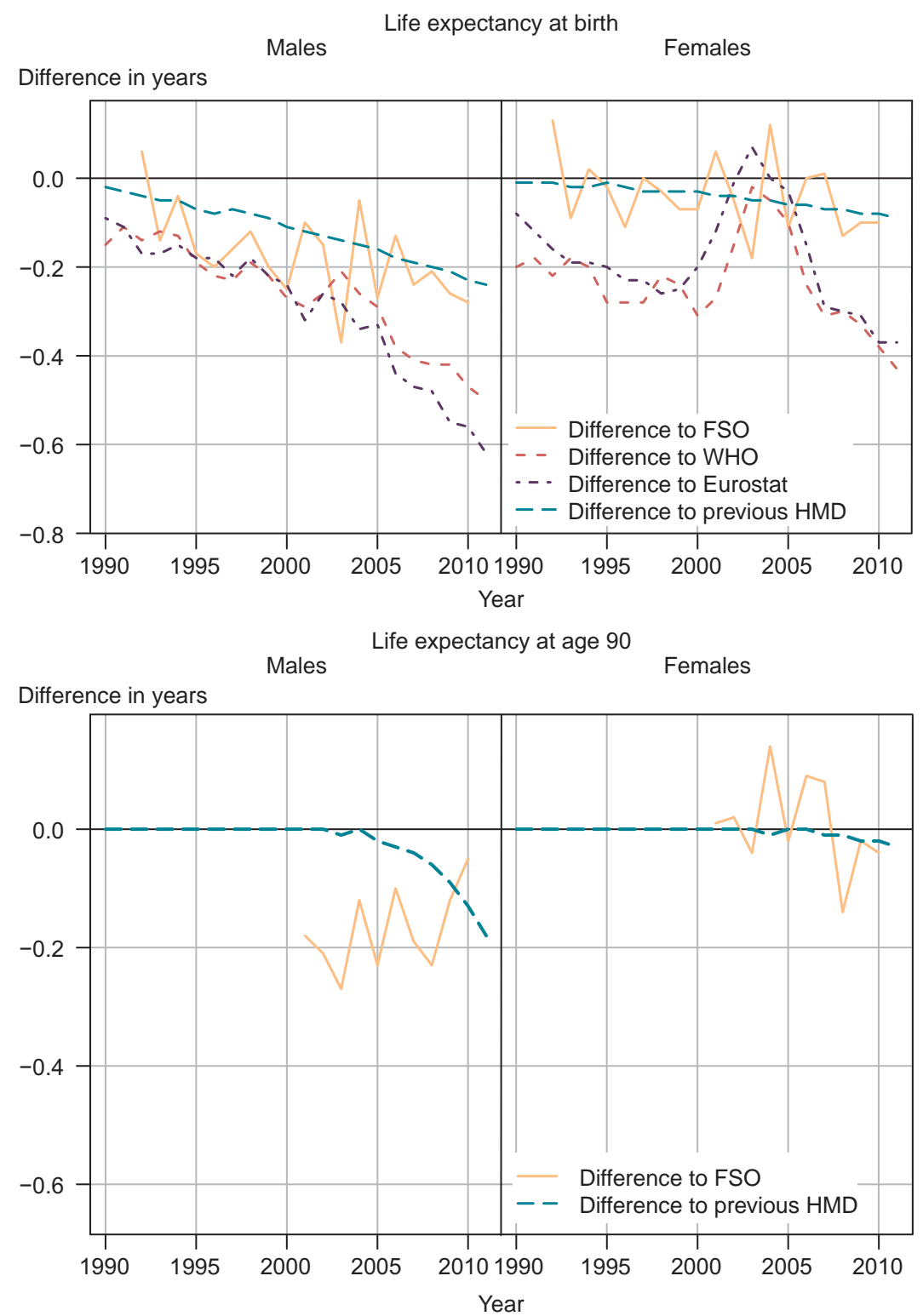

Note: The life expectancies from other sources to which we compare our numbers are always represented by the horizontal black line at level zero. If the lines representing the difference are below/ above zero, this implies that our adjusted life expectancies are below/above the numbers of the life expectancy data from other sources. FSO refers to the Federal Statistical Office. With the exception of the data from the FSO, which publishes three-year averages, all of the other sources provide annual numbers. For our comparison, the data for the FSO are centred on the middle of a three-year period. Source: Federal Statistical Office, WHO, Eurostat, HMD, own calculations 


\section{Discussion and Conclusion}

In this paper, we sought to generate detailed adjusted population estimates for Germany over the last inter-censal period by reassessing and enhancing existing approaches. Our findings contribute to the existing literature in several ways. First, using the German case as an example, we documented the challenges that globalised countries with relatively open borders face in keeping track of their population numbers. Second, our paper contributes to the debate on the challenges associated with the transition from performing full censuses to conducting register-based censuses (Coleman 2013; Martin 2006; Scholz/Kreyenfeld 2016; Valente 2010). The German case points to issues that may arise from such a transition. It is not clear whether the prior cleaning of statistics we detected in the years before the census was partly motivated by the upcoming enumeration. However, the preparation of the registers for the censuses provided incentives to implement corrections. If undertaking such procedures becomes "good" practise, countries will no longer have a single census date at which corrections are implemented, but rather a census period over several years in which more or less extensive adjustments are applied at different levels of the administrative hierarchy, and at varying points in time.

While it is generally desirable to adjust any inaccuracies in the population statistics as quickly as possible, such corrections become problematic if they account for errors that have persisted for longer periods. In this case, a comparison of the census outcomes with the old post-censal population estimates is likely to provide a distorted view of the cohorts, regions, and other subgroups for which it was particularly tricky to keep track of the population numbers during the inter-censal period. We were able to demonstrate this with the outcomes by cohort for East, West, and total Germany. Accurate information on these distortions is, however, very valuable. In addition to allowing us to identify and address shortcomings in the registration systems, this information is extremely useful for the backward-adjustment of inter-censal population estimates. Societies should have an interest in maintaining accurate population statistics, as information on the population distribution within a country is relevant for making decisions regarding public financial transfers and electoral representation.

A third contribution of our paper is that our evaluation of different adjustment methodologies offers important insights that can be used to improve generalised methodologies, such as those implemented in the HMD, to derive adjusted intercensal population estimates for globalised countries that are subject to substantial migration. For the German case, it is important to stress that any attempt to adjust the inter-censal population estimates over such a long period of time must be approximate. If we had been able to gain access to detailed migration data for the whole inter-censal period, we probably would have chosen to use one of the two approaches that take into account variation in migration intensities across age/cohort, sex, time, and region. But given the data limitations, we settled for the population-size-adjusted approach, as it seems to provide reasonable results, while it does not require the use of potentially erroneous migration data, some of which we were only able to estimate based on rather bold assumptions. Our finding that the out- 
comes of the population-size-adjusted approach do not vastly differ from those of other approaches that take variation in migration intensities into account reassures us that we made the most appropriate choice. This observation is also encouraging for the purposes of improving generalised methodologies, as it shows that even for a rather complicated case like Germany, a relatively simple approach seems to work reasonably well.

In comparing our preferred adjustment approach with the official adjustment approach (Statistisches Bundesamt 2016b), we previously noted that unlike our approach, the official approach is only carried out for the total population at the level of the German states. Our approach considers sex and age by single-year ages. In addition, while our adjustment covers the period between 1 January 1988 and 1 January 2011, the official adjustment covers the period between 31 December 1990 and 31 December 2010. The official estimates as of 31 December 2010 were, on the other hand, derived from backward estimations. In the official inter-censal adjustment, variation in migration intensities over time is taken into account; which is in line with our simplified migration-adjusted approach. If we had decided to focus on the 1990-2010 period only, we probably would have favoured this approach as well, as relatively rich migration data are available for this period. In deriving migration intensities, the prior cleaning is also considered in the official approach through estimation techniques. However, the official adjustment focuses on the 2008-2010 period only, whereas we also cover the cleaning in 2004. In addition, in the official adjustment, these estimates are only used to modify the migration intensities, while the estimated artificial migration events are not added to the accumulated error in the population estimates detected in the census. Overall, the official approach and our approach are similar in some ways and different in others. It is, however, reassuring that the officially adjusted total population estimates and the population numbers derived using our favoured approach do not differ greatly (see Fig. 5). The slight differences found in the levels seem to be mainly attributable to the fact that our adjustment starts three years earlier than the official adjustment.

Although our corrections and adjustments mainly concern cohorts with low mortality rates, their effects on life expectancy levels are not insubstantial. This is especially apparent when we compare our new calculations with the figures published in the international databases of the WHO and Eurostat, as it seems that no efforts were made by these organisations to adjust for problems in the population estimates for Germany during the 1990s and the 2000s. Our adjusted life expectancies at birth are up to 0.6 years lower for males and up to 0.45 years lower for females. The differences between these figures and the life expectancies previously published by the HMD and the Federal Statistical Office of Germany - both of which seem to have attempted to account for the shortcomings in the German population estimates - are smaller, but are still not negligible. We also integrated our adjusted population estimates into the Human Fertility Database. However, as the population estimates for women were less affected by accumulated errors than those for men, and given the low fertility levels in Germany, the effects of the adjustment on total fertility levels were rather small (maximum deviation of the TFR: +0.03 in East Germany without East Berlin). 
The adjusted population numbers for East, West, and total Germany, as well as for the 16 German states and East and West Berlin provided in the online data appendix, are expected to facilitate research that requires access to detailed time series of population exposure data. In addition, the lessons learned from the German case should be used to revisit the HMD methodology for dealing with the adjustment of population estimates in inter-censal periods. Nevertheless, an inter-censal period of more than two decades is problematic, and we hope that periods of this length remain exceptional in the decades to come.

\section{Acknowledgements}

We would like to thank Vladimir M. Shkolnikov and Domantas Jasilionis for their important input in the development of the inter-censal adjustment method, and the anonymous reviewers for their very helpful suggestions. Furthermore, we are very grateful for the data support we received from Sigrid Gellers-Barkmann, Karolin Kubisch, and the student assistants at the Laboratory of Demographic Data at the Max Planck Institute for Demographic Research. We would also like to acknowledge support from Olga Pötzsch and other contact persons at the German statistical offices, and to thank Miriam Hils for language editing. The study has been partly funded by the Deutsche Forschungsgemeinschaft (DFG) (Germany) (JA 2302/1-1), the Agence nationale de la recherche (ANR) (France) (ANR-12-FRAL-0003-01), and the Russian Academic Excellence Project «5-100».

\section{References}

Barbieri, Magali et al. 2015: Data Resource Profile: The Human Mortality Database (HMD). In: International Journal of Epidemiology 44,5: 1549-1556 [doi: 10.1093/ije/ dyv105].

Bell, Martin; Muhidin, Salut 2009: Cross-National Comparisons of Internal Migration (No. HDRP-2009-30). Human Development Research Paper Series 2009/30. New York: Human Development Report Office (HDRO), United Nations Development Programme (UNDP).

Castro-Martín, Teresa; Cortina, Clara 2015: Demographic Issues of Intra-European Migration: Destinations, Family and Settlement. In: European Journal of Population 31,2: 109-125 [doi: 10.1007/s10680-015-9348-y].

Coleman, David 2013: The Twilight of the Census. In: Population and Development Review 38,s1: 334-351 [doi: 10.1111/j.1728-4457.2013.00568.x].

Constant, Amelie F.; Massey, Douglas S. 2003: Self-Selection, Earnings, and Out-Migration: A Longitudinal Study of Immigrants to Germany. In: Journal of Population Economics 16,4: 631-653 [doi: 10.1007/s00148-003-0168-8].

Eppmann, Helmut 2004: Von der Volkszählung 1987 zum registergestützten Zensus 2010? Statistische Analysen und Studien NRW 17. Düsseldorf: Information und Technik Nordrhein-Westfalen (IT.NRW), Geschäftsbereich Statistik.

Ette, Andreas; Sauer, Leonore 2010: Auswanderung aus Deutschland. Wiesbaden: VS Verlag für Sozialwissenschaften, Springer Fachmedien Wiesbaden GmbH. 
FDZ (Forschungsdatenzentrum der Statistischen Ämter des Bundes und der Länder) 2014: Wanderungsstatistik 2000-2011. Wiesbaden: Statistisches Bundesamt.

Fritsch, Frederick N.; Carlson, Ralph E. 1980: Monotone Piecewise Cubic Interpolation. In: SIAM Journal on Numerical Analysis 17,2: 238-246 [doi: 10.1137/0717021].

Fuchs-Schündeln, Nicola; Schündeln, Matthias 2009: Who Stays, Who Goes, Who Returns? In: Economics of Transition 17,4: 703-738 [doi: 10.1111/j.1468-0351.2009.00373.x].

Grohmann, Heinz 2009: Von der Volkszählung zum Registerzensus: Paradigmenwechsel in der deutschen amtlichen Statistik. In: AStA Wirtschafts- und Sozialstatistisches Archiv 3,1: 3-23 [doi: 10.1007/s11943-009-0053-3].

Hannemann, Anke; Scholz, Rembrandt D. 2009: The Mortality of Non-Germans in Germany: A Comparison of Results Estimated from the Official Statistics and the Central Register of Foreigners. Rostock: Rostock Center for the Study of Demographic Change.

HFD (Human Fertility Database) 2017: Human Fertility Database. Rostock/Vienna: Max Planck Institute for Demographic Research (Germany) and Vienna Institute of Demography (Austria) [http://www.humanfertility.org, 19.02.2018].

HMD (Human Mortality Database) 2017: The Human Mortality Database. Berkeley/ Rostock: University of California, Berkeley/Max Planck Institute for Demographic Research [http://www.mortality.org/, 19.02.2018].

Hölder, Egon; Ehling, Manfred 1991: Zur Entwicklung der amtlichen Statistik in Deutschland. In: Fischer, Wolfram; Kunz, Andreas (Eds.): Grundlagen der Historischen Statistik von Deutschland. Wiesbaden: VS Verlag für Sozialwissenschaften: 15-31.

Jasilioniene, Aiva et al. 2016: Data Resource Profile: The Human Fertility Database. In: International Journal of Epidemiology 45,4: 1077-1078e [doi: 10.1093/ije/dyw135].

Jdanov, Dmitri; Scholz, Rembrandt D.; Shkolnikov, Vladimir M. 2005: Official Population Statistics and the Human Mortality Database Estimates of Populations Aged $80+$ in Germany and Nine Other European Countries. In: Demographic Research 13,14: 335 362 [doi: 10.4054/DemRes.2005.13.14].

Kaus, Wolfhard; Mundil-Schwarz, Rabea 2015: Die Ermittlung der Einwohnerzahlen und der demografischen Strukturen nach dem Zensus 2011. In: Wirtschaft und Statistik 2015,4: 18-38.

Klüsener, Sebastian; Zagheni, Emilio 2014: The East-West Gradient in Spatial Population Development within Germany: Temporary GDR Legacy versus Longstanding Spatial Disparities. In: Historical Methods: A Journal of Quantitative and Interdisciplinary History 47,4: 167-179 [doi: 10.1080/01615440.2014.955234].

Kreyenfeld, Michaela; Scholz, Rembrandt D. 2009: Fertility and Mortality Data for Germany: Recent Progress and Future Challenges. Berlin: German Council for Social and Economic Data (RatSWD).

Martin, David 2006: Last of the Censuses? The Future of Small Area Population Data. In: Transactions of the Institute of British Geographers 31,1: 6-18 [doi: 10.1111/j.14755661.2006.00189.x].

Meissner, Fran; Vertovec, Steven 2015: Comparing Super-Diversity. In: Ethnic and Racial Studies 38,4: 541-555. [doi: 10.1080/01419870.2015.980295].

Opfermann, Heike; Grobecker, Claire; Krack-Roberg, Elle 2006: Auswirkung der Bereinigung des Ausländerzentralregisters auf die amtliche Ausländerstatistik. In: Wirtschaft und Statistik 2006,5: 480-494. 
Scholz, Rembrandt; Kreyenfeld, Michaela 2016: The Register-Based Census in Germany: Historical Context and Relevance for Population Research. In: Comparative Population Studies 41,2: 175-204 [doi: 10.12765/CPoS-2016-08en].

Scholz, Rembrandt D.; Jdanov; Dmitri A. 2007: Nutzung der Daten des Forschungsdatenzentrums der Rentenversicherung zur wissenschaftlichen Mortalitätsanalyse: Verfahren zur Korrektur der Bevölkerungsbestände der amtlichen Statistik im hohen Alter in Deutschland. Paper presented at the Third Workshop of the Data Research Centre of the Pension Insurance from 26-28 June 2006 in Bens-heim, Germany.

Scholz, Rembrandt; Jdanov, Dmitri 2008: Weniger Hochbetagte als gedacht: Korrekturen in der amtlichen Statistik für Westdeutschland notwendig. In: Demografische Forschung aus erster Hand 5,1: 4.

Scholz, Rembrandt et al. 2017: About Mortality Data for Germany (Last Update: April 21 1nd, 2017). Berkeley/Rostock: University of California, Berkeley/Max Planck Institute for Demographic Research [http://www.mortality.org/hmd/DEUTNP/InputDB/ DEUTNPcom.pdf, 19.02.2018].

Statistisches Bundesamt 1993: Bevölkerungsstatistische Übersichten 1946-1989. Heft 3, Sonderreihe mit Beiträgen für das Gebiet der ehemaligen DDR. Wiesbaden: Statistisches Bundesamt.

Statistisches Bundesamt 2006: Statistisches Jahrbuch 2006 für die Bundesrepublik Deutschland. Wiesbaden: Statistisches Bundesamt.

Statistisches Bundesamt 2014: Bevölkerung und Erwerbstätigkeit: Wanderungen. Wiesbaden: Statistisches Bundesamt.

Statistisches Bundesamt 2016a: Wanderungen: Qualitätsbericht. Wiesbaden: Statistisches Bundesamt.

Statistisches Bundesamt 2016b: Bevölkerung und Erwerbstätigkeit: Rückgerechnete und fortgeschriebene Bevölkerung auf Grundlage des Zensus 2011. Wiesbaden: Statistisches Bundesamt.

Valente, Paolo 2010: Census Taking in Europe: How are Populations Counted in 2010? In: Population \& Societies 467: 1-4.

von der Lippe, Peter 2006: Brauchen wir noch selbständige Statistische Landesämter neben dem Statistischen Bundesamt in Deutschland? In: Jahrbuch für Wirtschaftswissenschaften/Review of Economics 57,2: 190-211.

Wheldon, Mark C. et al. 2016: Bayesian Population Reconstruction of Female Populations for Less Developed and More Developed Countries. In: Population Studies 70,1: 21-37 [doi: 10.1080/00324728.2016.1139164].

Wilmoth, John R. et al. 2007: Methods Protocol for the Human Mortality Database: Version 5. Berkeley/Rostock: University of California, Berkeley/Max Planck Institute for Demographic Research. 
Sebastian Klüsener ( $₫)$. Max Planck Institute for Demographic Research. Rostock, Germany; Vytautas Magnus University. Kaunas, Lithuania.

E-mail: kluesener@demogr.mpg.de

URL: https://www.demogr.mpg.de/en/institute/staff_directory_1899/sebastian kluesener_1644.htm

Pavel Grigoriev, Rembrandt D. Scholz. Max Planck Institute for Demographic Research. Rostock, Germany.

E-mail: grigoriev@demogr.mpg.de,scholz@demogr.mpg.de

URL: https://www.demogr.mpg.de/en/institute/staff_directory_1899/pavel_ grigoriev 1578.htm

URL: https://www.demogr.mpg.de/de/institut/mitarbeiter_1899/rembrandt_d_scholz_663. htm

Dmitri A. Jdanov. Max Planck Institute for Demographic Research. Rostock, Germany; National Research University Higher School of Economics. Moscow, Russia. E-mail: jdanov@demogr.mpg.de

URL: https://www.demogr.mpg.de/en/institute/staff_directory_1899/dmitri_a_ jdanov_516.htm 


\section{Comparative Population Studies}

WWW.comparativepopulationstudies.de

ISSN: 1869-8980 (Print) - 1869-8999 (Internet)

\section{Published by}

Prof. Dr. Norbert F. Schneider

Federal Institute for Population Research D-65180 Wiesbaden / Germany

\section{(cc) BY-SA}

2018

\section{Managing Editor}

Dr. Katrin Schiefer

\section{Copy Editor}

Dr. Evelyn Grünheid

Dr. Katrin Schiefer

\section{Editorial Assistant}

Beatriz Feiler-Fuchs

Wiebke Hamann

\section{Layout \\ Beatriz Feiler-Fuchs \\ E-mail:cpos@bib.bund.de}

\section{Scientific Advisory Board}

Karsten Hank (Cologne)

Michaela Kreyenfeld (Berlin)

Marc Luy (Vienna)

Peter Preisendörfer (Mainz)

Nikola Sander (Wiesbaden)

Zsolt Spéder (Budapest)

Rainer Wehrhahn (Kiel)

\section{Board of Reviewers}

Martin Abraham (Erlangen)

Laura Bernardi (Lausanne)

Hansjörg Bucher (Bonn)

Claudia Diehl (Konstanz)

Andreas Diekmann (Zurich)

Gabriele Doblhammer-Reiter (Rostock)

Jürgen Dorbritz (Wiesbaden)

Anette Eva Fasang (Berlin)

E.-Jürgen Flöthmann (Bielefeld)

Alexia Fürnkranz-Prskawetz (Vienna)

Beat Fux (Salzburg)

Joshua Goldstein (Berkeley)

Sonja Haug (Regensburg)

Hill Kulu (Liverpool)

Aart C. Liefbroer (The Hague)

Kurt Lüscher (Konstanz)

Emma Lundholm (Umeå)

Nadja Milewski (Rostock)

Dimiter Philipov (Vienna)

Roland Rau (Rostock)

Tomáš Sobotka (Vienna)

Jeroen Spijker (Barcelona)

Olivier Thévenon (Paris)

Helga de Valk (Brussels)

Heike Trappe (Rostock)

Michael Wagner (Cologne) 